\title{
AN INVESTIGATION OF GENE ACTION AND GENOTYPE $\times$ ENVIRONMENT INTERACTION IN TWO CROSSES OF NICOTIANA RUSTICA BY TRIPLE TEST CROSS AND INBRED LINE ANALYSIS
}

\author{
H. S. POONI, J. L. JINKS and N. E. M. JAYASEKARA* \\ Department of Genetics, University of Birmingham, Birmingham B15 2TT
}

Received 18.i.78

\begin{abstract}
Summary
Data from two random samples of inbred lines and from the two sets of the triple test cross in which these inbreds are crossed to the pure-breeding parents and $F_{1}$ of the cross from which they were derived, one involving material derived from the cross between varieties 1 and 5 of Nicotiana rustica and the other material from the cross between varieties 2 and 12, are analysed and the results compared to those reported earlier. Detection of epistasis and the estimation of the additive and dominance components of variation among the triple test cross families is based on the orthogonal analysis of Jinks and Perkins (1970) while the additive component is also estimated directly from the inbred families. Tests are carried out to detect genotype $\times$ microenvironment interaction in the $L_{1}$ and $L_{2}$ families of the triple test cross and in the inbred families and the interaction partitioned into that involving additive and dominance gene action. Their relationship with the corresponding additive and dominance components of mean performance is investigated by linear regression analysis.

As expected the material from the $V_{1} \times V_{5}$ cross segregates at loci the alleles of which display large additive effects but little or no dominance and epistasis while dominance and epistasis are larger components of the genetic variation in $V_{2} \times V_{12}$ cross. In both crosses, the micro-environmental interaction involves mainly the additive genetic component. For some characters there is evidence of independent segregation of genes controlling environmental sensitivity.

Estimates of the additive genetic component D from the triple test cross and the inbred families, are consistent for all the characters in both crosses. The triple test cross analysis, therefore, provides satisfactory estimates of the genetic variation among a random set of inbred lines, even for those characters which display non-allelic interactions.
\end{abstract}

\section{INTRODUCTION}

ThE triple test cross breeding programme, an extension of North Carolina. Design III (Comstock and Robinson, 1952) proposed by Kearsey and Jinks (1968) and subsequently extended by Jinks, Perkins and Breese (1969) and Jinks and Perkins (1970), has been extensively applied to detect and estimate the components of the genetic variation in material derived from crosses between varieties 1 and 5 and 2 and 12 of the Birmingham Nicotiana rustica collection (Perkins and Jinks, 1970, 1971; Jayasekara, 1974; Pooni, 1976, and Pooni and Jinks, 1976). Detection of genotype $\times$ environment interaction both with the macro and micro-environments has also been

* Present address: Department of Genetics, Rubber Research Institute, Nivitigalakale, Matugama, Sri Lanka. 
carried out and attempts made to partition these interactions into those involving the additive and the dominance action of the genes (Perkins and Jinks, 1970). All these studies, however, were largely limited to illustrating the new techniques for detecting and estimating the genetical and genotype $x$ environment interaction components of variation as exemplified by the analysis of flowering time and final height. A comprehensive survey of the genetic variation in these Nicotiana rustica crosses has therefore been undertaken using the optimal material, namely, random inbred lines derived from them.

\section{THE EXPERIMENT}

The experiment consists of two separate triple test crosses. The first, based on material derived from the cross between varieties 1 and 5 of Nicotiana rustica, was initiated during $1972 / 73$ by crossing $V_{1}$ and $V_{5}$ and their $\mathrm{F}_{1}(1 \times 5)$ to each of the $82, \mathrm{~F}_{11}$ inbreds derived by single seed descent from the $\mathrm{F}_{2}$ of the $V_{1} \times V_{5}$ cross (Perkins and Jinks, 1973) to give the $L_{1}$, $L_{2}$ and $L_{3}$ families of a triple test cross, respectively. Each of these $82 \times 3$

\section{TABLE 1}

$A$ list of the morphological and seed characters scored for the present material

$\begin{array}{rll} & \text { Character } & \text { Description } \\ 1 & \mathrm{H}_{1} & \text { Plant height }(\mathrm{cm}) \text { at } 2 \text { weeks after planting in the field } \\ 2 & \mathrm{H}_{2} & \text { Plant height }(\mathrm{cm}) \text { at } 4 \text { weeks after planting in the field } \\ 3 & \mathrm{H}_{3} & \text { Plant height }(\mathrm{cm}) \text { at } 6 \text { weeks after planting in the field } \\ 4 & \text { FT } & \text { Flowering time in days from the date of sowing } \\ 5 & \text { HFT } & \text { Height in } \mathrm{cm} \text { at the time of flowering } \\ 6 & \text { CL } & \text { Corolla length in cm of the first flower } \\ 7 & \text { SSP } & \text { Stamen-stigma positioning in the first flower } \\ 8 & \text { LL } & \text { Length of the largest leaf blade at flowering time }(\mathrm{cm}) \\ 9 & \text { LW } & \text { Width of the largest leaf blade at flowering time }(\mathrm{cm}) \\ 10 & \text { LS } & \text { Plant diameter across the largest pair of leaves at flowering time }(\mathrm{cm}) \\ 11 & \text { FH } & \text { Height of the plant at the end of the season }(\mathrm{cm}) \\ 12 & \mathrm{CN} & \text { Number (count) of seed bearing capsules at the end of the season } \\ 13 & \text { SW } & \text { Weight of the total seed produced by } 10 \text { randomly chosen } \\ & & \text { capsules of a plant }\left(\mathrm{g} \times 10^{-4}\right) \\ 14 & \text { ASW } & \text { Hundred seed weight for each plant } \\ 15 & \text { TSN } & \text { Total seed number per plant in thousands }\end{array}$

crosses and the selfs of the 82 inbreds were raised in a single experiment during the summer of 1973. The experiment was divided into two equal blocks and five individually randomised plants were raised for each family in each block. Data were recorded for the 15 morphological and seed characters listed in table 1 .

The second triple test cross was based on material derived from the cross between varieties $V_{2}$ and $V_{12}$. Again the $60, \mathrm{~F}_{7}$ inbreds derived by single seed descent from the $\mathrm{F}_{2}$ generation of the $V_{2} \times V_{12}$ cross (see Jinks, Jayasekara and Boughey, 1977) were crossed to $V_{2}, V_{12}$ and their $\mathrm{F}_{1}$ $(12 \times 2)$ to produce the $L_{1}, L_{2}$ and $L_{3}$ families of a triple test cross, respectively. These 180 families together with the 60 inbred selfs were grown during 1975 in a single experiment with two blocks. Five individually randomised plants were raised for each family in each block. The material, however, was scored for only eight of the 15 characters listed in table 1 . 


\section{The Epistatic, Additive And dominance components}

The tests for epistatic, additive and dominance components were those described by Jinks and Perkins (1970) in which the appropriate block (replicate) interaction is used to test the significance of the three components if this interaction is itself significant against the error derived from the variation within families. The results obtained for the test for epistasis are given in table 2 for both crosses.

\section{TABLE 2}

Variance ratios testing the significance of epistasis $\left(\mathrm{L}_{1 \mathrm{i}}+\overline{\mathrm{L}}_{2^{\mathrm{i}}}-2 \overline{\mathrm{L}}_{3 \mathrm{i}}\right.$ variance) in the triple test cross analyses of the material from $\mathrm{V}_{1} \times \mathrm{V}_{5}$ and $\mathrm{V}_{2} \times \mathrm{V}_{12}$ crosses of Nicotiana rustica varieties

\begin{tabular}{|c|c|c|}
\hline Character & $V_{1} \times V_{5}$ cross & $V_{2} \times V_{12}$ cross \\
\hline $\mathrm{H}_{1}$ & $1 \cdot 26^{\mathrm{Ns}}$ & $1.95 * *$ \\
\hline $\mathrm{H}_{2}$ & $1 \cdot 38^{\mathrm{NS}}$ & $2 \cdot 72 * * *$ \\
\hline $\mathrm{H}_{3}$ & $1 \cdot 29^{\mathrm{Ns}}$ & $3 \cdot 00 * * *$ \\
\hline FT & $1 \cdot 03 \mathrm{Ns}$ & $1.78 * * *$ \\
\hline HFT & $<1.00^{\mathrm{Ns}}$ & $1 \cdot 09^{\mathrm{Ns}}$ \\
\hline $\mathrm{LL}$ & $<1 \cdot 00^{\mathrm{Ns}}$ & $1 \cdot 46 * *$ \\
\hline LW & $1 \cdot 03 \mathrm{Ns}$ & $1 \cdot 23 \mathrm{Ns}$ \\
\hline LS & $1 \cdot 03^{\mathrm{Ns}}$ & - \\
\hline FH & $1 \cdot 14^{\mathrm{Ns}}$ & $1 \cdot 75 * *$ \\
\hline CL & $1 \cdot 37^{*}$ & - \\
\hline SSP & $<1 \cdot 00^{\mathrm{Ns}}$ & - \\
\hline GN & $<1.00^{\mathrm{Ns}}$ & - \\
\hline SW & $1 \cdot 24 \mathrm{Ns}$ & - \\
\hline ASW & $1 \cdot 30 *$ & - \\
\hline TSN & $<1 \cdot 00^{\mathrm{Ns}}$ & - \\
\hline
\end{tabular}

Ns $\mathrm{P}>0.05 ; * \mathrm{P}=0.05-0.01 ; * * \mathrm{P}=0.01-0.001 ; * * * \mathrm{P}<0.001 ;-=$ results not available.

The between sums (additive) and between differences (dominance) mean squares provide estimates of $\sigma_{m}^{2}$ and $\sigma_{m 1}^{2}$ (hereafter referred to as $\sigma_{s}^{2}$ and $\sigma_{d}^{2}$ ), which in the absence of epistasis and linkage disequilibrium in this special case of randomly inbred populations with equal gene frequencies, equal $\frac{1}{4} D=\frac{1}{4} \Sigma d^{2}$ and $\frac{1}{4} H=\frac{1}{4} \Sigma h^{2}$, respectively (Kearsey and Jinks, 1968). In the presence of epistasis, however, these expectations include epistatic terms and these estimates of $D$ and $H$ become:

$$
\begin{aligned}
D & =\Sigma d_{i}^{2}+\frac{1}{4} \Sigma i_{j k}^{2}+\frac{13}{16} \Sigma j_{j k}^{2}+\frac{1}{9} \Sigma l_{j k}^{2}+\Sigma d_{j} \Sigma j_{j k}^{*}-\frac{2}{3}\left[\Sigma d j \Sigma j_{k j}\right]^{*}+\frac{1}{3}\left[\Sigma i_{j k} l_{j k}\right] \\
& -\frac{2}{3}\left[\Sigma j_{j k} j_{k j}\right]+\frac{1}{2} \Sigma j_{j k} j_{j s}+\left[\Sigma j_{j k}\left(\frac{2}{9} \Sigma j_{s k}-\frac{1}{3} \Sigma j_{k s}-\frac{1}{3} \Sigma j_{s j}\right)\right] \\
H & =\Sigma h_{i}^{2}+\frac{1}{2} \Sigma i_{j k}^{2}+\frac{1}{2} \Sigma l_{j k}^{2}+\frac{1}{4} \Sigma j_{j k}^{2}+\Sigma l_{j k}\left(h_{j}+h_{k}\right)^{*}-\left[\Sigma i_{j k}\left(h_{j}+h_{k}\right)\right]^{*} \\
& -\left[\Sigma i_{j k} l_{j k}\right]+\frac{1}{2}\left[\Sigma j_{j k} j_{k j}\right]+\frac{1}{2}\left[\Sigma i_{j k}\left(\Sigma i_{j s}+\Sigma i_{k s}\right)\right] \\
& +\frac{1}{2}\left[\Sigma i_{j k}\left(\Sigma l_{j s}+\Sigma l_{k s}\right)\right]+\frac{1}{2}\left[\Sigma l_{j k}\left(\Sigma l_{j s}+\Sigma l_{k s}\right)\right]
\end{aligned}
$$

All the genetic effects are as defined by Mather and Jinks (1971) on the $\mathrm{F}_{\infty}$ metric (Van der Veen, 1959). The expectations given in square brackets ([]) are dependent on the coefficient of gene association and the asterisked co-products alone may change their direction with the type of epistasis present (Pooni, 1976).

The variation among the inbred families included in these experiments can be partitioned into three items; between inbred families, inbred 
families $\times$ blocks and the error derived from the variation within families and the appropriate tests of significance applied. The significance of the "between inbred families" component provides an independent test of $D=\Sigma d_{i}^{2}$ and a direct estimate of its value. In the presence of epistasis this estimate of $D$ will equal $\Sigma d_{i}^{2}+\Sigma i_{j k}^{2}$.

The estimates of $D$ obtained from the triple test cross and from the inbred families and the estimates of $H$ obtained from the triple test cross are listed for both the crosses in table 3 .

\section{Micro-environmental interaction}

The $L_{1}$ and $L_{2}$ families in both triple test crosses being $\mathrm{F}_{1}$ families show no segregation. The variation within each family is entirely environmental in origin and in the absence of micro-environmental interactions these variances are expected to be homogeneous over all $L_{1 i}$ or $L_{2 i}$ families since all are then estimates of $E_{1}$, the additive environmental variance. A significant heterogeneity between the "within" variances of $L_{1 i}$ or $L_{2 i}$ families is therefore evidence of differential genotypic sensitivity to the micro-environmental variation. This is also true for the variation within the true breeding lines. Any differential genotypic sensitivity among the true-breeding lines, however, can only arise from interactions with additive genetic effects while the differential sensitivity of the $L_{1}$ or $L_{2}$ families may involve dominance effects also.

Two estimates of within family variance (one from each block) are available for any inbred, $L_{1 i}$ or $L_{2 i}$ family for most of the characters and these have been pooled for individual families before carrying out the Bartlett test of homogeneity. Characters CN, SW, ASW and TSN, however, were scored only for the first block and for these the test of homogeneity was carried out on the single estimate of the variance.

The results of the Bartlett test for both the crosses are given in table 4 as $\chi_{(n-1)}^{2}$ values and their significances. These tests, however, only detect the presence of genotype $\times$ micro-environmental interactions, and they do not indicate their cause. Such interactions can arise from pleiotropic effects of the genes segregating for mean performance or by segregation at independent loci which control environmental sensitivity only. Furthermore, the loci controlling mean performance and sensitivity may or may not be in linkage equilibrium. Pleiotropy and linkage disequilibrium will produce a relationship between the mean performance (family mean) and sensitivity (within family variance). If a linear regression analysis is therefore carried out using the family mean as independent and the standard deviation as dependent variable, for the inbred families the regression mean square will indicate the degree of linear dependence of the additive genetic $\times$ micro-environment interaction on the additive genetic variation and the remainder mean square, the degree of independent control of this interaction. For all except four of the characters both mean squares can be tested against the families $\times$ blocks interaction mean square which provides an estimate of error for the standard deviations.

The genotype $\times$ micro-environment interaction present amongst $L_{1 i}$ and $L_{2 i}$ families, on the other hand, can be partitioned between the additive genetic and dominance effects (Perkins and Jinks, 1971) and their linear 


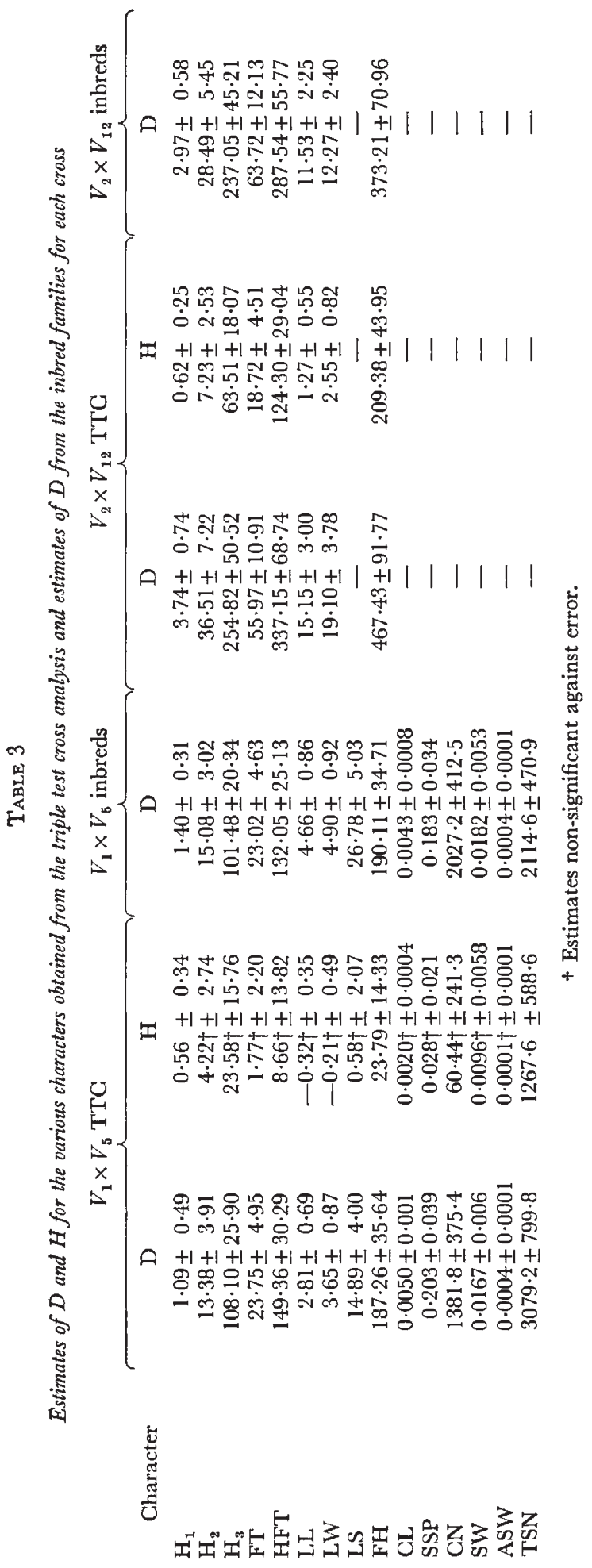




\section{TABLE 4}

Significance of genotype $\times$ micro-environmental variation within $\mathrm{L}_{1} \mathrm{i}, \mathrm{L}_{2 \mathrm{i}}$ and inbred families as detected by Bartlett's test of heterogeneity for various characters scored on the material from $\mathrm{V}_{1} \times \mathrm{V}_{5}$ and $\mathrm{V}_{2} \times \mathrm{V}_{12}$ crosses

\begin{tabular}{|c|c|c|c|c|c|c|}
\hline \multirow[b]{2}{*}{ Character } & \multicolumn{3}{|c|}{$V_{1} \times V_{5}$ material } & \multicolumn{3}{|c|}{$V_{2} \times V_{12}$ material } \\
\hline & $\begin{array}{c}L_{1} \text { fams } \\
\chi^{2}(81)\end{array}$ & $\begin{array}{c}L_{2} \text { fams } \\
\chi^{2}(81)\end{array}$ & $\begin{array}{c}\text { Inbreds } \\
\chi^{2}(81)\end{array}$ & $\begin{array}{c}L_{1} \text { fams } \\
\chi^{2}{ }_{(58)}\end{array}$ & $\begin{array}{c}L_{2} \text { fams } \\
\chi^{2} \text { (59) }\end{array}$ & $\begin{array}{c}\text { Inbreds } \\
\chi^{2}(58)\end{array}$ \\
\hline $\mathrm{H}_{1}$ & $104 \cdot 08 *$ & $115 \cdot 41 * *$ & $165 \cdot 13 * * *$ & $87 \cdot 04 *$ & $50 \cdot 71^{\mathrm{Ns}}$ & $133.06 * * *$ \\
\hline $\mathrm{H}_{2}$ & $100 \cdot 21^{\mathrm{Ns}}$ & $118 \cdot 67 * *$ & $165 \cdot 20 * * *$ & $141 \cdot 96^{*}$ & $53 \cdot 38^{\mathrm{Ns}}$ & $178 \cdot 08 * * *$ \\
\hline $\mathrm{H}_{3}$ & $103 \cdot 24 *$ & $68 \cdot 13^{\mathrm{Ns}}$ & $115.66 * * *$ & $93 \cdot 99 * *$ & $98 \cdot 78 * * *$ & $101 \cdot 52 * * *$ \\
\hline $\mathrm{FT}$ & $117 \cdot 70 * *$ & $126 \cdot 08 * * *$ & $230 \cdot 23 * * *$ & $103 \cdot 71 * * *$ & $199 \cdot 38 * * *$ & $231 \cdot 25 * * *$ \\
\hline HFT & $138 \cdot 74 * * *$ & $76 \cdot 49^{\mathrm{Ns}}$ & $200 \cdot 00 * * *$ & $137 \cdot 03 * * *$ & $135 \cdot 32 * * *$ & $147 \cdot 10^{*} * *$ \\
\hline LL & $95 \cdot 10^{\mathrm{Ns}}$ & $76 \cdot 78^{\mathrm{Ns}}$ & $115 \cdot 67 * * *$ & $66 \cdot 55^{\mathrm{Ns}}$ & $81 \cdot 74 *$ & $104 \cdot 22 * * *$ \\
\hline $\mathrm{LW}$ & $102 \cdot 67 \mathrm{Ns}$ & $95 \cdot 73^{\mathrm{Ns}}$ & $112 \cdot 52 * * *$ & $82 \cdot 87 * *$ & $75 \cdot 37^{\mathrm{Ns}}$ & $100 \cdot 45 * * *$ \\
\hline LS & $97 \cdot 35^{\mathrm{Ns}}$ & $68 \cdot 80^{\mathrm{Ns}}$ & $117 \cdot 02 * * *$ & - & - & - \\
\hline $\mathrm{FH}$ & $110 \cdot 38 *$ & $88 \cdot 85^{\mathrm{Ns}}$ & $126 \cdot 20 * * *$ & $104 \cdot 61 * * *$ & $71 \cdot 99 \mathrm{Ns}$ & $129 \cdot 46 * * *$ \\
\hline $\mathrm{CL}$ & $104 \cdot 15^{*}$ & $98 \cdot 45^{\mathrm{Ns}}$ & $72 \cdot 10^{\mathrm{Ns}}$ & - & - & - \\
\hline SSP & $86 \cdot 76^{\mathrm{Ns}}$ & $58 \cdot 06^{\mathrm{Ns}}$ & $431 \cdot 02 * * *$ & - & - & - \\
\hline $\mathrm{CN}$ & $109 \cdot 33 * *$ & $119 \cdot 23^{*}$ & $108 \cdot 14 * *$ & - & - & - \\
\hline SW & $110.99 *$ & $100 \cdot 70^{\mathrm{Ns}}$ & $131 \cdot 60 * * *$ & - & - & $\ldots$ \\
\hline ASW & $80 \cdot 59^{\mathrm{Ns}}$ & $97 \cdot 06^{\mathrm{Ns}}$ & $122 \cdot 58 * * *$ & $\ldots$ & - & - \\
\hline TSN & $105.96 *$ & $131 \cdot 52 * * *$ & $176.03 * * *$ & - & - & - \\
\hline
\end{tabular}

Ns $\mathrm{P}>0.05 ; * \mathrm{P}=0.05-0.01 ; * * \mathrm{P}=0.01-0.001 ; * * * \mathrm{P}<0.001 ;-$ results not available.

relationship determined independently by regressing $\frac{1}{2}\left(\sigma L_{1 i}+\sigma L_{2 i}\right)$ on to $\frac{1}{2}\left(L_{1 i}+\bar{L}_{2 i}\right)$ and $\frac{1}{2}\left(\sigma L_{1 i}-\sigma L_{2 i}\right)$ on to $\frac{1}{2}\left(L_{1 i}-L_{2 i}\right)$ respectively. Again, with four exceptions the regression and remainder mean squares can be tested for their significance against the corresponding blocks interaction mean squares. The results of these analyses are given in tables 5 and 6 for the $V_{1} \times V_{5}$ and $V_{2} \times V_{12}$ crosses respectively. For the four characters CN, SW, ASW and TSN (in the $V_{1} \times V_{5}$ cross) the regression mean squares have: been tested against the corresponding remainder mean squares.

\section{INTERPRETATION AND CONCLUSION}

(i) Gene action

Reference to table 2 and to the estimates of $H$ in table 3 shows that for the material derived from the $V_{1} \times V_{5}$ cross epistasis and dominance effects are either non-significant or of marginal significance only. On the other hand, there is ample evidence of an additive component of variation which is highly significant for all the characters irrespective of the source of its estimate. This material therefore segregates at loci, the alleles of which display little dominance or epistasis but exhibit comparatively large additive effects. Similar results for this material have been reported by Perkins and Jinks (1970) and Jinks and Perkins (1970) for two characters, flowering time (FT) and final height (FH).

For the material from the $V_{2} \times V_{12}$ cross there is significant epistasis for six out of the eight characters (table 2) and the estimates of the additive and dominance components are highly significant for all characters (table 3 ). Non-allelic interaction and dominance therefore constitute a common feature of the genetic variation in this cross. The estimates of additive $(D)$ and dominance $(H)$ components, however, will not be the true magnitudes 
TRIPLE TEST CROSS ANALYSIS

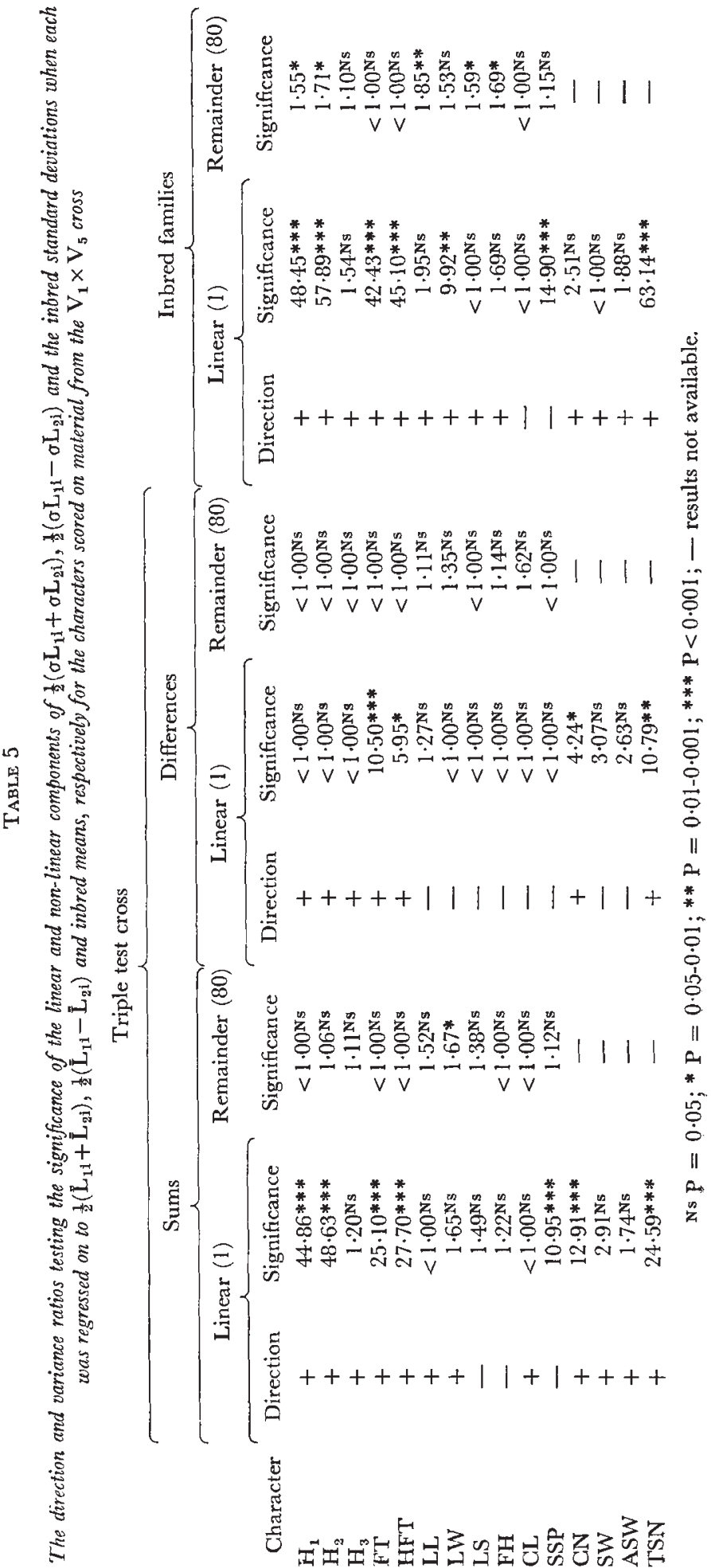




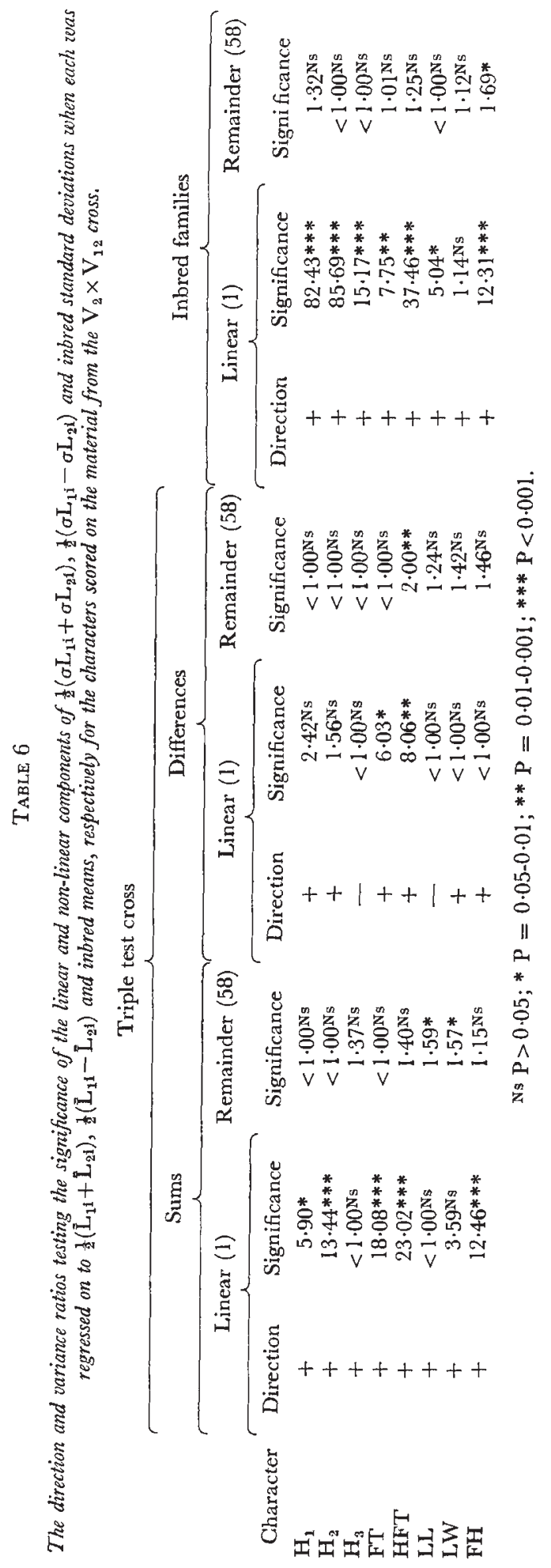


of $\Sigma d_{i}^{2}$ and $\Sigma h_{i}^{2}$ as they will contain the epistatic effects given earlier (see Section 3).

The two estimates of $D$, one from the triple test cross and the other from the analysis of the inbred families, are consistent in magnitude for all characters in both crosses (table 3). Both estimate $\Sigma d_{i}^{2}$ in the absence of epistasis, but in its presence they are affected by non-allelic interactions in different ways as shown by the expectations in Section 3 (Pooni, 1976). It follows, therefore, that in the present data the contributions of the epistatic effects to these two estimates of $D$ must be of the same order of magnitude in every case. Thus over two quite contrasting crosses and widely differing characters the estimate of $D$ from the triple test cross is always a satisfactory estimate of the genetic variation among the random inbred lines even in the presence of epistasis.

\section{(ii) Genotype $\times$ micro-environment interaction}

The results in table 4 confirm the widespread occurrence of genotype $\times$ micro-environment interactions in both crosses. However, the material from $V_{2} \times V_{12}$ cross seems to be the more interactive in that 19 of the 24 tests conducted show significant heterogeneity among the within family variances compared with 28 out of 45 tests for the material from the $V_{1} \times V_{5}$ cross. Furthermore, most of this environmental sensitivity is positively related to mean performance (tables 5 and 6). This can only arise from pleiotropy or strong linkage disequilibrium at most of the loci controlling mean performance and environmental sensitivity. Evidence for independent segregation at loci controlling environmental sensitivity is confined to a few cases where the remainder mean square is found to be significant against the error (tables 5 and 6). Independent segregation of mean performance and genotypic sensitivity to micro-environmental variation is also reported by Perkins and Jinks (1973) for some morphological characters recorded on $V_{1} \times V_{5}$ material.

It can also be seen from table 4 that the $\chi_{(n-1)}^{2}$ for heterogeneity more often takes a significant value for the inbred family variances than for those of the $L_{1 i}$ or $L_{2 i}$ families for both crosses. Furthermore, the inbred families also display a more marked linear dependence. It must be remembered, however, that the $\chi_{(n-1)}^{2}$ for heterogeneity have different expectations in the inbred and $L_{1}$ and $L_{2}$ families. In the inbred families the genotype $\times$ environment interactions have the expectation of $\Sigma g d_{i j}^{2}$ while in the $L_{1}$ and $L_{2}$ families they are $\frac{1}{4} \Sigma g_{d i j}^{2}+\frac{1}{4} \Sigma g_{h i j}^{2}-\frac{1}{2} \Sigma g_{d i j} g_{h i j}$ and $\frac{1}{4} \Sigma g_{d i j}^{2}+\frac{1}{4} \Sigma g_{h i j}^{2}+\frac{1}{2} \Sigma g_{d i j} g_{h i j}$ respectively, where $g_{d i j}$ is the interaction with the additive genetic effect and $g_{h i j}$ the interaction with the dominance effect (Perkins and Jinks, 1970). Similarly, the variation in mean performance on to which they are regressed has the expectation $\Sigma d_{i}^{2}$ for the inbreds, $\frac{1}{4} \Sigma d_{i}^{2}+\frac{1}{4} \Sigma h_{i}^{2}-\frac{1}{2} \Sigma d_{i} h_{i}$ for the $L_{1}$ families and $\frac{1}{4} \sum d_{i}^{2}+\frac{1}{4} \sum h_{i}^{2}+\frac{1}{2} \sum d_{i} h_{i}$ for the $L_{2}$ families.

Finally, dominance $\times$ micro-environment interactions are rarely significant in this material and whenever they are they always display a significant linear relationship with the dominance deviations for the mean performance. The performance of the heterozygotes is therefore more stable than that of the corresponding homozygotes in both the crosses and 
any differences in sensitivity there are in the heterozygotes are largely associated with differences in mean performance.

Acknowledgments.--The statistical analysis was carried out on the Birmingham University 1906A computer.

\section{REFERENCES}

COMSTOCK, R. E., AND ROBINSON, H. F. 1952. Estimation of average dominance of genes Heterosis, Chapter 30. Iowa State College Press.

JAYASEKARA, N. E. M. 1974. Analysis of interactions in Nicotiana rustica. Ph.D. Thesis. University of Birmingham.

JiNks, J. L., JAYASEKara, N. E. M., AND Boughey, H. 1977. Joint selection for both extremes of mean performance and of sensitivity to a macro-environmental variable. II. Single seed descent. Heredity, 39, 345-355.

JINKS, J. L., AND PERKINS, J. M. 1970. A general method for the detection of additive, dominance and epistatic components of variation. III. $\mathrm{F}_{2}$ and backcross populations. Heredity, 25, 419-429.

JINKS, J. L., PERKINS, J. M., AND BREESE, E. L. 1969. A general method of detecting additive, dominance and epistatic variation for metrical traits. II. Application to inbred lines. Heredity, 24, 45-57.

KEARSEY, M. J., AND JINKS, J. L. 1968. A general method for the detection of additive, dominance and epistatic components of variation for metrical traits. I. Theory. Heredity, 23, 403-409.

MATHER, K., AND JiNKs, J. L. 1971. Biometrical Genetics. Chapman and Hall, London.

PERKINS, J. M., AND JINKS, J. L. 1970. Detection and estimation of genotype-environmental, linkage and epistatic components of variation for a metrical trait. Heredity, 25, 157-177.

PERKINS, J. M., AND JINKS, J. L. 1971. Analysis of genotype $\times$ environment interaction in triple test cross data. Heredity, 26, 203-209.

PERKINS, J. M., AND JINKS, J. L. 1973. The assessment and specificity of environmental and genotype-environmental components of variability. Heredity, 30, 111-126.

Pooni, H. s. 1976. Exploitation of inbreds in Nicotiana rustica. Ph.D. Thesis, University of Birmingham.

Pooni, H. s., AND JINKS, J. L. 1976. The efficiency and optimal size of triple test cross designs for detecting epistatic variation. Heredity, 36, 215-227.

VAN DER VEEN, J. H. 1959. Tests of non-allelic interaction and linkage for quantitative characters in generations derived from two diploid pure lines. Genetica, 30, 201-232. 